\title{
Artificial disc replacement versus fusion in patients with cervical degenerative disc disease with radiculopathy: 5-year outcomes from the National Swedish Spine Register
}

\author{
Anna MacDowall, MD, PhD, ${ }^{1}$ Martin Skeppholm, MD, PhD, ${ }^{2,3}$ Lars Lindhagen, ${ }^{4}$ \\ Yohan Robinson, MD, PhD, MBA, ${ }^{1}$ Håkan Löfgren, MD, PhD, ${ }^{5}$ Karl Michaëlsson, MD, PhD, ${ }^{1}$ and \\ Claes Olerud, MD, PhD' 1

\begin{abstract}
${ }^{1}$ Department of Surgical Sciences, Uppsala University, Uppsala; ${ }^{2}$ Department of Learning, Informatics, Management and Ethics (LIME), Medical Management Center, Health Economics and Health Evaluation Research Group, Karolinska Institutet, Stockholm; ${ }^{3}$ Center for Spine Surgery in Stockholm, Sophiahemmets Sjukhus, Stockholm; ${ }^{4}$ Uppsala Clinical Research Center, Uppsala University, Uppsala; and ${ }^{5}$ Department of Neuro-Orthopaedic Center, Jönköping, Sweden
\end{abstract}

\begin{abstract}
OBJECTIVE The long-term efficacy of artificial disc replacement (ADR) surgery compared with fusion after decompression for the treatment of cervical degenerative disc disease and radiculopathy has not previously been investigated in a population-based setting.

METHODS All patients with cervical degenerative disc disease and radiculopathy who were in the national Swedish Spine Registry (Swespine) beginning in January 1, 2006, were eligible for the study. Follow-up information was obtained up to November 15, 2017. The authors compared, using propensity score matching, patients treated with anterior decompression and insertion of an ADR with patients who underwent anterior decompression combined with fusion surgery. The primary outcome was the Neck Disability Index (NDI), a patient-reported function score ranging from $0 \%$ to $100 \%$, with higher scores indicating greater disability and a minimum clinically important difference of $>15 \%$.
\end{abstract}

RESULTS A total of 3998 patients (2018:1980 women/men) met the inclusion criteria, of whom 204 had undergone arthroplasty and 3794 had undergone fusion. After propensity score matching, 185 patients with a mean age of 49.7 years remained in each group. Scores on the NDI were approximately halved in both groups after 5 years, but without a significant mean difference in NDI $(3.0 \% ; 95 \% \mathrm{Cl}-8.4$ to $2.4 ; p=0.28)$ between the groups. There were no differences between the groups in EuroQol-5 Dimensions or in pain scores for the neck and arm.

CONCLUSIONS In patients with cervical degenerative disc disease and radiculopathy, decompression plus ADR surgery did not result in a clinically important difference in outcomes after 5 years, compared with decompression and fusion surgery.

https://thejns.org/doi/abs/10.3171/2018.7.SPINE18657

KEYWORDS artificial disc replacement; treatment outcome; Neck Disability Index; cervical radiculopathy; adjacent-segment pathology; degenerative

$\mathrm{C}$ ERVICAL radiculopathy is characterized by radiating pain from the neck to the shoulder or arm and is typically the consequence of degenerative changes such as disc herniation and osteophyte formation, with lower cervical segments most frequently affected..$^{10}$ When treatment with pain medication and physiotherapy has failed there are several surgical treatment options available, the most common being anterior cervical decompression and fusion (ACDF). Artificial disc replacement (ADR) was invented to preserve motion at the index level, to prevent development of adjacent-segment degenerative pathology (ASP).${ }^{10}$ Half of all spine surgeons questioned worldwide

ABBREVIATIONS ACDF = anterior cervical decompression and fusion; $A D R=$ artificial disc replacement; $A S P=$ adjacent-segment degenerative pathology; $B M I=$ body mass index; EQ-5D = EuroQol-5 Dimensions; IDE = investigational device exemption; NDI = Neck Disability Index; PROM = patient-reported outcome measure; RCT = randomized controlled trial; SD = standard deviation; Swespine = Swedish Spine Registry; VAS = visual analog scale.

SUBMITTED May 23, 2018. ACCEPTED July 12, 2018.

INCLUDE WHEN CITING Published online November 2, 2018; DOI: 10.3171/2018.7.SPINE18657. 
TABLE 1. Baseline characteristics before and after propensity score matching

\begin{tabular}{|c|c|c|c|c|c|c|}
\hline \multirow[b]{2}{*}{ Covariate } & \multicolumn{3}{|c|}{ Before Matching } & \multicolumn{3}{|c|}{ After Matching } \\
\hline & ADR, $n=204$ & Fusion, $n=3794$ & $p$ Value & $A D R, n=185$ & Fusion, $n=185$ & $\mathrm{p}$ Value \\
\hline Male $(\%)^{*}$ & $105(51.5)$ & $1875(49.4)$ & 0.61 & $92(49.7)$ & $104(56.2)$ & 0.21 \\
\hline Age, yrs, mean (SD)* & $46.4(8.2)$ & $49.9(9.2)$ & $<0.001$ & $46.9(8.0)$ & $47.5(8.8)$ & 0.50 \\
\hline Smoking $(\%)^{*}$ & $38(18.6)$ & $667(17.6)$ & 0.73 & $36(19.5)$ & $41(22.2)$ & 0.52 \\
\hline $\mathrm{BMI}$, mean $(\mathrm{SD})^{*}$ & $25.8(3.6)$ & $26.9(4.7)$ & 0.001 & $26.0(3.6)$ & $26.2(4.0)$ & 0.58 \\
\hline Unemployed $(\%)^{*}$ & $18(8.8)$ & $438(11.5)$ & 0.23 & $18(9.7)$ & $21(11.4)$ & 0.61 \\
\hline Sick leave $(\%)^{*}$ & $83(40.7)$ & $1794(47.3)$ & 0.059 & $78(42.2)$ & $73(39.5)$ & 0.60 \\
\hline Disability pension $(\%)^{*}$ & $71(34.8)$ & $1325(34.9)$ & 0.93 & $67(36.2)$ & $75(40.5)$ & 0.39 \\
\hline No. of levels, mean (SD)* & $1.24(0.5)$ & $1.35(0.5)$ & 0.004 & $1.26(0.5)$ & $1.23(0.4)$ & 0.49 \\
\hline Positive attitude to returning to work (\%)* & $180(88.2)$ & $3186(84.0)$ & 0.10 & $161(87.0)$ & $157(84.9)$ & 0.55 \\
\hline Preop NDI, mean (SD)* & $39.4(15.8)$ & $44.0(17.1)$ & $<0.001$ & $40.7(15.5)$ & $40.4(18.1)$ & 0.89 \\
\hline Retired (\%) & $3(1.5)$ & $280(7.4)$ & 0.004 & $3(1.6)$ & $10(5.4)$ & 0.062 \\
\hline Heavy work (\%) & $45(22.1)$ & $1035(27.3)$ & 0.096 & $42(22.7)$ & $42(22.7)$ & 1.00 \\
\hline Hospital time, days, mean (SD) & $2.1(1.1)$ & $2.2(1.7)$ & 0.28 & $2.14(1.1)$ & $2.45(1.4)$ & 0.017 \\
\hline Fine motor skill disability (\%) & $116(56.9)$ & $2620(69.1)$ & $<0.001$ & $107(57.8)$ & $120(64.9)$ & 0.17 \\
\hline EQ-5D, mean (SD) & $0.4(0.3)$ & $0.4(0.3)$ & 0.18 & $0.40(0.3)$ & $0.42(0.3)$ & 0.59 \\
\hline VAS neck, mean (SD) & $5.3(2.6)$ & $5.9(2.5)$ & $<0.001$ & $5.5(2.6)$ & $5.6(2.6)$ & 0.86 \\
\hline VAS arm, mean (SD) & $5.2(2.4)$ & $5.7(2.6)$ & 0.003 & $5.3(2.3)$ & $5.6(2.7)$ & 0.31 \\
\hline
\end{tabular}

Values are expressed as the number of patients (\%) or the mean value (SD), as indicated.

* Selected confounders used for propensity score matching.

chose this optional treatment instead of fusion in the belief that ADR prevents ASP. ${ }^{4}$ More than 100,000 patients in the US receive a cervical ADR device each year. ${ }^{18}$ Several nonblinded investigational device exemption (IDE) studies comparing ADR devices with fusion surgery have shown clinical noninferiority in patient-reported outcome measures (PROMs). ${ }^{2,5,8,15,16,22,24}$ In contradiction to the intended purpose of cervical motion preservation devices, no protection against ASP has been realized in practice. ${ }^{19}$

The national Swedish Spine Registry (Swespine) was founded in 1993 and cervical spine procedures have been included in it since 2006. ${ }^{26}$ With use of the Swespine register, the primary aim of this study was to compare the 5 -year clinical outcome difference in Neck Disability Index (NDI) in patients with cervical degenerative disc disease and radiculopathy who had been treated with ADR compared with patients treated with fusion surgery. Secondary outcomes were the EuroQol-5 Dimensions (EQ5D) health survey findings and pain scores.

\section{Methods \\ Trial Design}

In this register-based cohort study we obtained prospectively collected data for all Swedish patients undergoing surgery on the cervical spine who had been registered in Swespine since the registration of cervical procedures started on January 1, 2006. Follow-up information was obtained up to November 15,2017 . Inclusion criteria were cervical disc herniation with radiculopathy or foraminal stenosis with radiculopathy, which had been surgically treated with anterior decompression followed either by insertion of an ADR or by fusion with either a plate with autograft/allograft, a stand-alone cage, or a cage with plate. Exclusion criteria were previous cervical spine surgery, symptoms of myelopathy, cervical malformation, or marked instability. All patients participating in a randomized controlled trial (RCT) comparing ADR with fusion (ISRCTN, registration number 44347115) ${ }^{11}$ were excluded.

\section{Data Collection and Outcomes}

Patients completed baseline characteristic questionnaires and postal follow-up questionnaires as well as validated PROMs without any assistance from the surgeon. ${ }^{7,26,27}$ Preoperative data included age, sex, BMI, smoking habits, working status, sick leave status, duration of neck pain, fine motor skills, and PROMs including NDI, EQ-5D, and the 10-grade visual analog scale (VAS) scores obtained separately for arm and neck pain. The attitude toward returning to work after surgery was investigated with the following question: "Do you think you will be able to return to your previous work after the surgery?" The surgeon recorded surgical data including diagnosis, surgical treatment method, surgical levels involved, neurological impairment, Ranawat grading, ${ }^{23}$ Frankel grading, ${ }^{6}$ instability of the cervical spine, type of implant, and any eventual perioperative complications. Follow-up questionnaires and PROMs were sent to the patients after $1,2,5$, and 10 years postoperatively.

The primary outcome (i.e., the NDI score) is a 10-item self-administered questionnaire measuring disability in patients with neck pain. The questions measure daily activities (e.g., the ability to dress, lift heavy objects, read, work, drive a car, sleep, and perform leisure-time activities) as well as concentration abilities and the severity of pain and headache. Each item is scored from 0 to 5 . The 


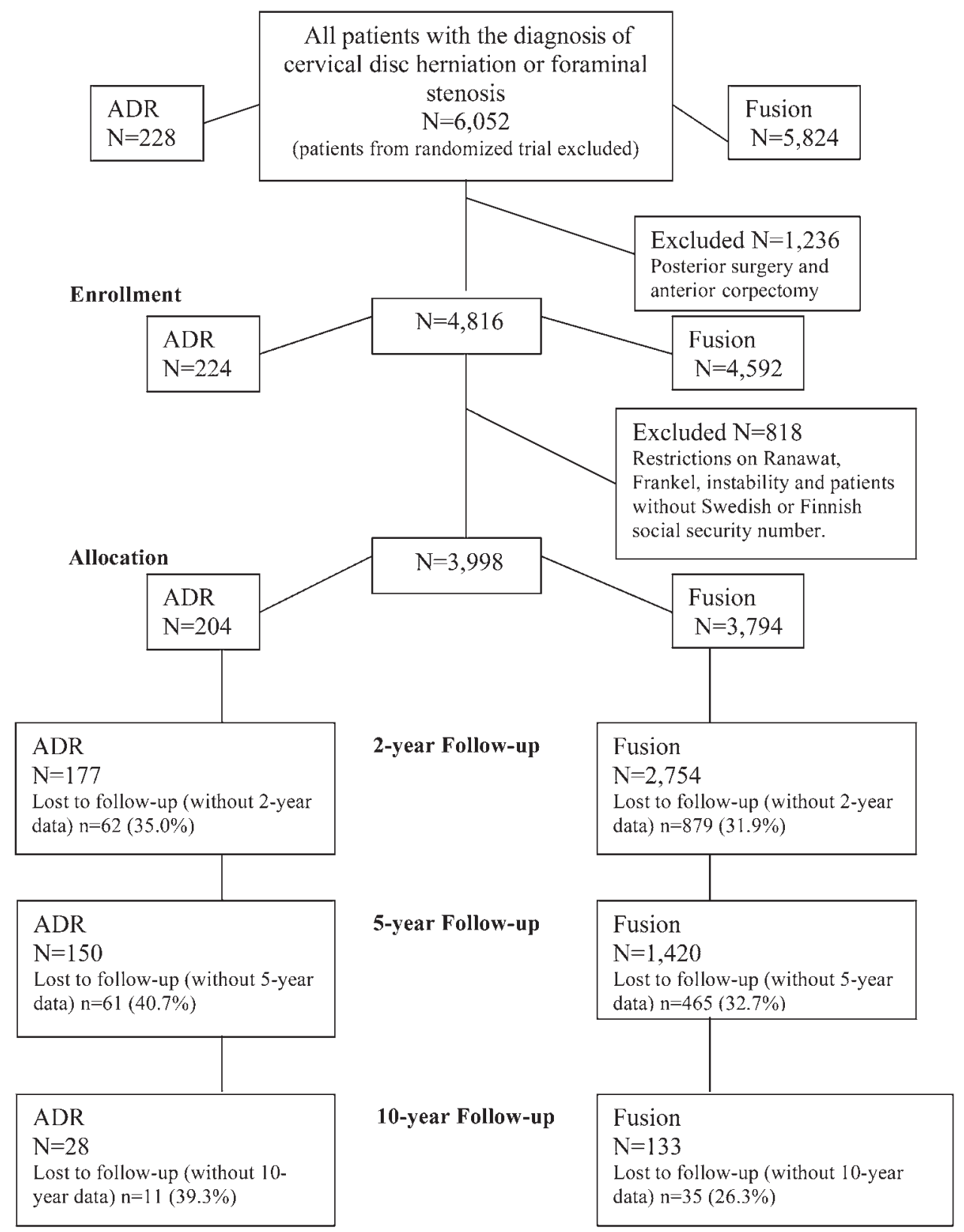

FIG. 1. Consolidated Standards for Reporting of Trials (CONSORT) diagram.

maximum score is 50 points, indicating severe disability, and the minimum score is 0 , indicating no disability. In order to handle missing items, the score is transformed into a percentage by doubling the total score (range 0\%$100 \%) .{ }^{21}$ The minimum clinically important difference in NDI is $15 \%-17 \%, 3,21,29$ with a standard deviation (SD) in similar series of $17 \% .^{11}$

Secondary outcomes were the EQ-5D scores (ranging from -0.5 to 1 , with higher scores reflecting a better quality of life), ${ }^{26} \mathrm{EQ}-5 \mathrm{D}$ health scores (ranging from 0 to 100 , with higher scores indicating better health), and VAS scores for neck and arm pain ${ }^{13}$ (ranging from 0 to 10, with higher scores indicating more severe pain). The minimum clinically important difference is 2.5 for VAS of the neck and for VAS of the arm. ${ }^{3}$

\section{Study Oversight}

The study was approved by the local Swedish ethics review board. Since 1998 the Swespine protocol has been entirely patient based, and all participants provide oral and written informed consent. The Swespine register is owned and governed by the Swedish Society of Spinal Surgeons (www.4s.nu) with public financial support. The authors designed the trial, analyzed the data, wrote the manuscript (with the first draft written by the first author), made the decision to submit the manuscript for publication, and vouch for the completeness and accuracy of the data and analysis. No institution or company had a role in collecting or analyzing the data, preparing the manuscript, or in the decision to submit the manuscript for publication. 


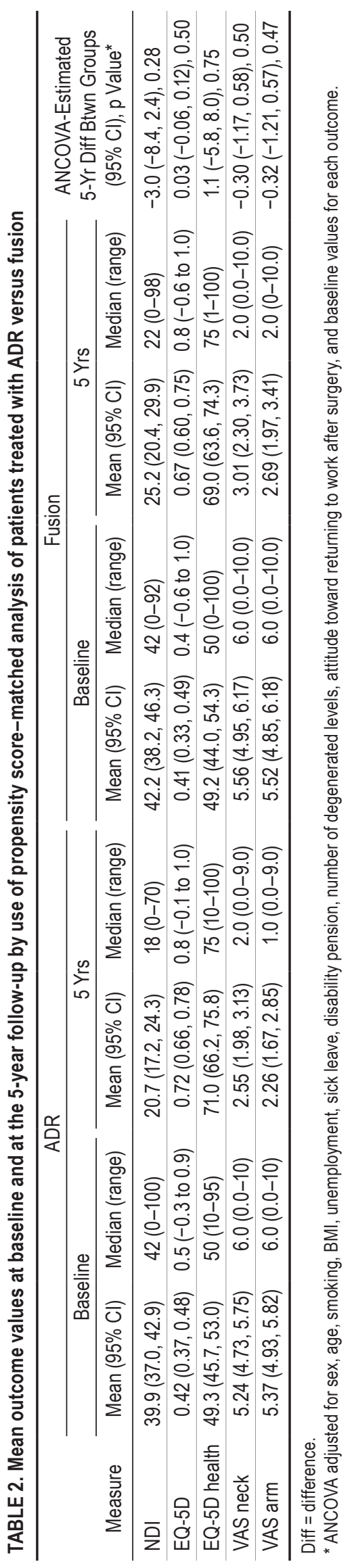

\section{Statistical Analysis}

Missing values were replaced with multiple imputation performed using chained equations as implemented in the $\mathrm{R}$ package MICE, ${ }^{28}$ generating 100 imputations. These imputations were analyzed one at a time, pooling the results using Rubin's rules. ${ }^{28}$ The following imputation models were used: predictive mean matching for numerical variables, logistic regression for dichotomous variables, and ordinal regression for ordinal variables. The proportion of missing values ranged from $0.1 \%$ for "number of degenerative levels" to $16.8 \%$ for "attitude towards returning to work after surgery."

To select confounders that might give rise to treatment selection bias, we used present knowledge and a directed acyclic graph. ${ }^{9}$ A propensity score was constructed to control for the following potential covariates: sex, age (continuous), smoking (current vs no smoking at present), body mass index (BMI; continuous; $\mathrm{kg} / \mathrm{m}^{2}$ ), unemployed (yes vs no), sick leave (yes vs no), disability pension (yes vs no), number of degenerated levels (1 to 4), the attitude toward returning to work after surgery (positive vs negative), and preoperative NDI (continuous).

Patients were then matched one to one based on estimated propensity scores limited by the requirement that the difference between scores should be no larger than 0.001, surgery should have taken place within 180 days, and follow-up NDI should be available. Matching was performed using logistic regression models with ADR as the outcome and the confounders as explanatory variables. The mean and SD for numerical variables and the numbers and percentages for categorical variables before and after matching were calculated, together with a $\mathrm{p}$ value for the null hypothesis of equal distributions. Time plots were made illustrating primary and secondary outcomes after 1, 2, 5, and 10 years of follow-up. Using ANCOVA, we compared the mean 5-year outcome values between the treatment groups, adjusted for the covariates included in the propensity score and also for the baseline values for each outcome. The mean differences of the 5-year values between the groups are presented with a 95\% CI and $p$ value. A positive mean difference corresponds to higher values for ADR (compared with fusion). In addition, all available cases were analyzed, including all patients who had completed each postal follow-up, with imputation for missing data.

Follow-up of tertiary outcome variables was investigated for all available cases by using linear regression for the numerical variables age and BMI (results presented as mean differences between the groups); logistic regression for the dichotomous variables of retirement, sick leave, disability pension, improvement of fine motor skills, working status, and heavy work (results presented as odds ratios, with fusion surgery used as the reference); and ordinal regression for postoperative sick leave and satisfaction index (odds ratios).

The mean number of complications and secondary surgeries was computed for all available cases for each group and compared using unadjusted and adjusted linear regression analysis. Reoperations on the index level and the adjacent levels were analyzed separately. We analyzed time to revision surgery by using a Kaplan-Meier plot. 

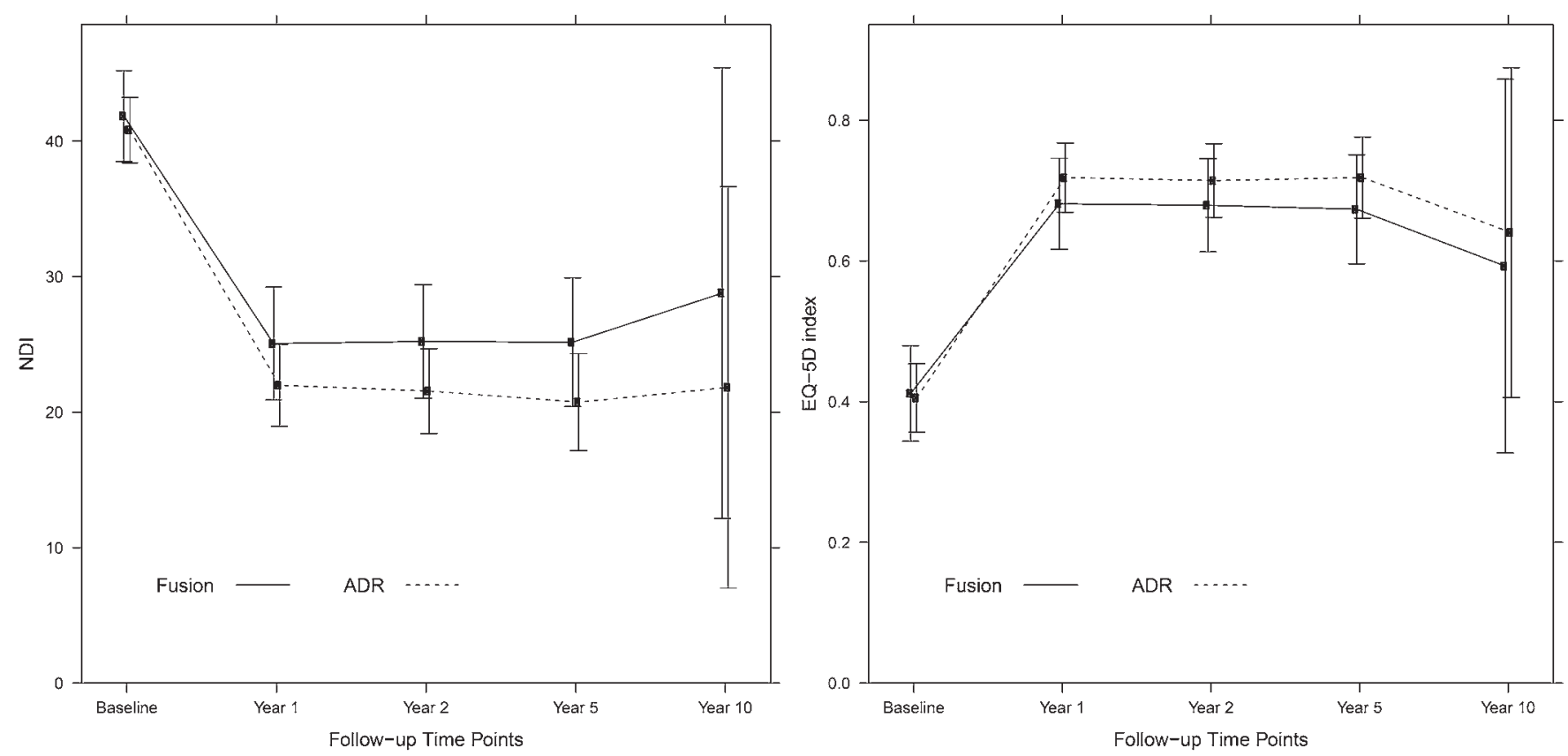

FIG. 2. Propensity score-matched data: ADR versus fusion. Time plot diagrams showing the mean values of the NDI (left) and the EQ-5D (right) at each time point. Error bars correspond to $95 \%$ Cls.

All statistical analyses were performed in $\mathrm{R}$, version 3.1.0 (http://www.R-project.org/; R Foundation for Statistical Computing).

\section{Results}

We enrolled 6052 patients, of whom 3998 met the inclusion criteria. Anterior decompression and insertion of an ADR had been performed in 204 patients (mean age 46 years), of whom 100 (49\%) were women and 105 (51\%) were men. A total of 3794 patients (mean age 50 years) had undergone ACDF, including 1919 (51\%) women and $1875(49 \%)$ men. The percentages of smokers and patients on sick leave were similar in both groups, whereas fine motor skills were less impaired in the arthroplasty group (57\%) than in the fusion group (69\%). The attitude toward returning to work after surgery was slightly more positive in the arthroplasty group (88\%) compared with the fusion group (84\%). The hospital stay was $2.1 \pm 1.1$ days for the arthroplasty group and $2.2 \pm 1.7$ days for the fusion group (Table 1). All the patients observed had not fulfilled all the follow-up time requirements. There were 2535/3416 (74\%) responding patients with a 1-year followup, 1990/2931 (68\%) patients with a 2-year follow-up, and 1044/1570 (67\%) patients with a 5-year follow-up (Fig. 1). After propensity score matching, 185 patients with 5 years of follow-up remained in each group and there was a good covariate balance between the groups.

The cervical levels involved were allocated within the propensity score-matched patient groups as follows: C3-4, 6 (1.6\%); C3-5, 1 (0.3\%); C4-5, 24 (6.5\%); C4-6, 11 (3.0\%); C4-7, 3 (0.8\%); C5-6, 123 (33.2\%); C5-7, 70 (18.9\%); C6-7, 121 (32.7\%); C6-T1, 2 (0.5\%); and C7-T1, $8(2.2 \%)$. The arthroplasty devices used were Discovery (DePuy), 24; Bryan Cervical Disc (Medtronic), 18;
ProDisc-C (Synthes Spine), 18; Prestige Cervical Disc (Medtronic), 12; Secure-C Disc (Globus), 7; Baguera-C (SpineArt), 8; and Kineflex-C (Southern Medical), 6. Information about the remaining 92 devices used in arthroplasties was not registered, but 79 of them were performed at the same hospital where Discovery (DePuy), Baguera-C (SpineArt), Bryan Cervical Disc (Medtronic), M6 (Spinal Kinetics), and Kineflex-C (Southern Medical) arthroplasties were used during the observed time period.

\section{Outcomes at 5 Years}

The ADR group improved in NDI from 39.9 (95\% CI $37.0-42.9$ ) to 20.7 (95\% CI 17.2-24.3) and the fusion group from 42.2 (95\% CI 38.2-46.3) to 25.2 (95\% CI 20.4-29.9), with a mean difference of $-3.0(95 \% \mathrm{CI}-8.4$ to $2.4 ; \mathrm{p}=$ 0.28) (Table 2, Fig. 2).

There were no mean differences between groups in EQ-5D $(0.03 ; 95 \% \mathrm{CI}-0.06$ to $0.12 ; \mathrm{p}=0.50)$, VAS neck $(-0.30 ; 95 \% \mathrm{CI}-1.17$ to $0.58 ; \mathrm{p}=0.50)$, or VAS arm $(-0.32 ; 95 \% \mathrm{CI}-1.21$ to $-0.57 ; \mathrm{p}=0.47)$ scores (Table 2$)$.

\section{Tertiary Follow-Up Variables and Secondary Surgery}

There were fewer patients in the arthroplasty group who reported dysphagia in the first 3 months after surgery than there were in the fusion group (OR $0.61 ; 95 \% \mathrm{CI}$ $0.41-0.92 ; \mathrm{p}=0.019)$. We observed no other differences between the groups for other tertiary outcome variables, such as BMI, working status, sick leave, disability pension, fine motor skills, and satisfaction index.

There were, however, more adverse events in the arthroplasty group (15/100 operations) than in the fusion group (5/100 operations; $p<0.001$ for the difference between the groups). The most common adverse events in the ADR group that demanded immediate intervention were post- 
TABLE 3. Reoperations for the ADR and fusion groups, nonmatched Swespine cohort

\begin{tabular}{lccc}
\hline \multicolumn{1}{c}{ Factor } & ADR, $\mathrm{n}=204$ & Fusion, $\mathrm{n}=3794$ & Crude Diff $(95 \% \mathrm{Cl}), \mathrm{p}$ Value \\
\hline Periop complications & $30(14.7 \%)$ & $197(5.2 \%)$ & $0.10(0.06,0.15),<0.001$ \\
\hline Early reop & $0(0 \%)$ & $17(0.4 \%)$ & $-0.00(-0.01,0.01), 0.45$ \\
\hline Secondary surgery, index level & $13(6.4 \%)$ & $55(1.5 \%)$ & $0.05(0.03,0.07),<0.001$ \\
\hline Secondary surgery, ASP & $3(1.5 \%)$ & $58(1.5 \%)$ & $-0.00(-0.02,0.02), 0.90$ \\
\hline Total reops & $16(7.8 \%)$ & $130(3.4 \%)$ & $0.04(0.02,0.07), 0.002$ \\
\hline
\end{tabular}

operative hematoma (4/100 operations), extraction or repositioning of the device (3/100 operations), residual stenosis (1/100 operations), and dural tear (1/100 operations). In the fusion group the most common adverse events were postoperative hematoma (1/100 operations), dural tear (1/100 operations), and residual stenosis (1/100 operations). There was no difference between groups for secondary surgery on the adjacent levels, with 1/100 ADR surgeries and 2/100 fusion surgeries $(\mathrm{p}=0.90)$. The total number of reoperations was higher in the arthroplasty group, with $8 / 100$ operations compared with $3 / 100$ operations in the fusion group $(\mathrm{p}=0.002)$ (Table 3, Fig. 3 [Kaplan-Meier curve]).

\section{Sensitivity Analysis Without Propensity Score Matching}

The results of the imputation analyses of all available cases were similar to those of the propensity score matching, with no clinically significant difference between groups after 5 years of follow-up (Table 4).

\section{Discussion}

This is the first observational study from a national spine registry conducted using PROMs that report longterm PROM findings after surgery with cervical ADR devices compared with anterior fusion. We found no significant clinical differences in patient satisfaction between the groups, but we found a higher degree of adverse events after surgery with ADR devices.

Before propensity score matching, there were clear indications of selection differences between the patient

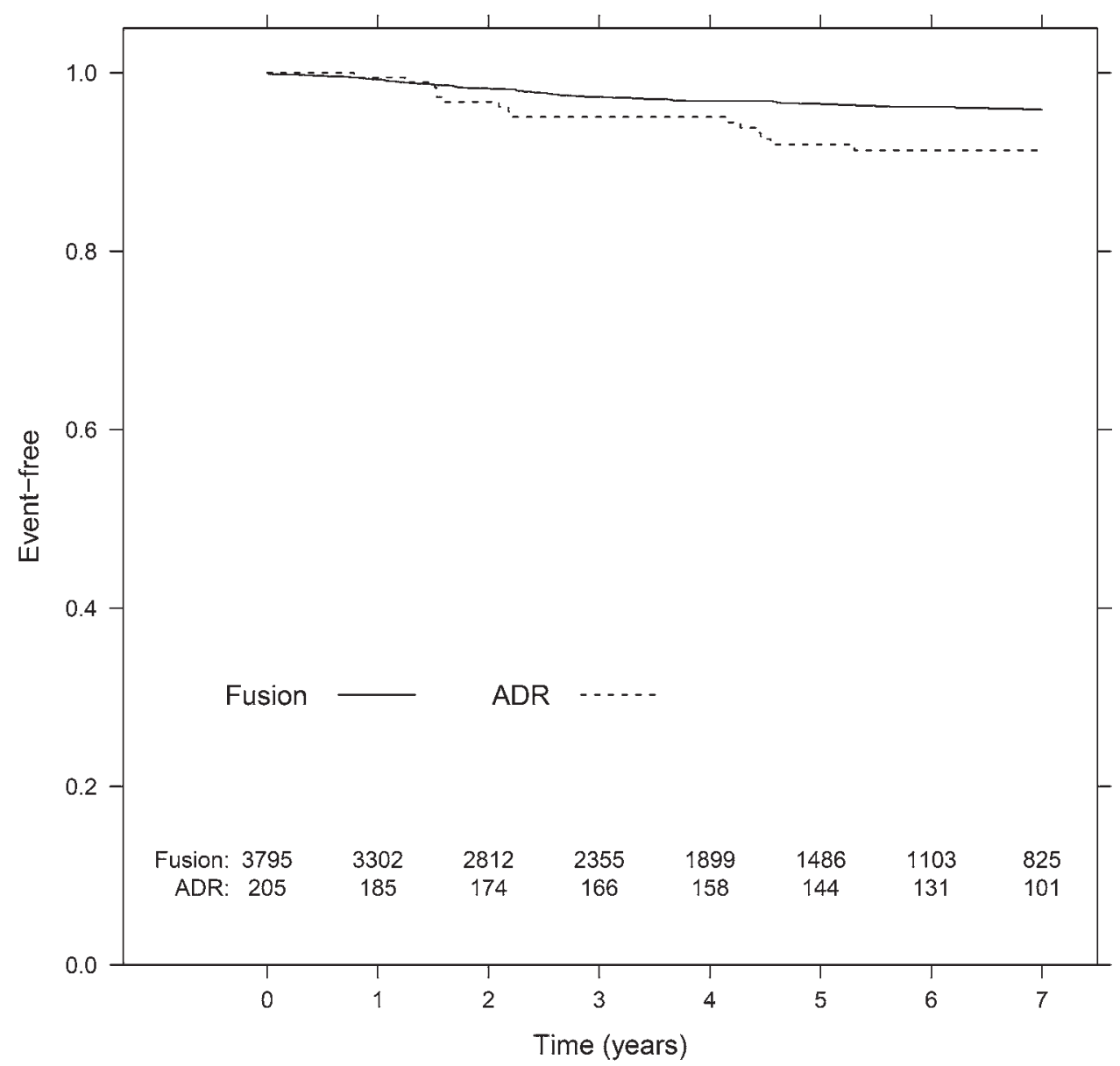

FIG. 3. Kaplan-Meier plot for reoperations. 


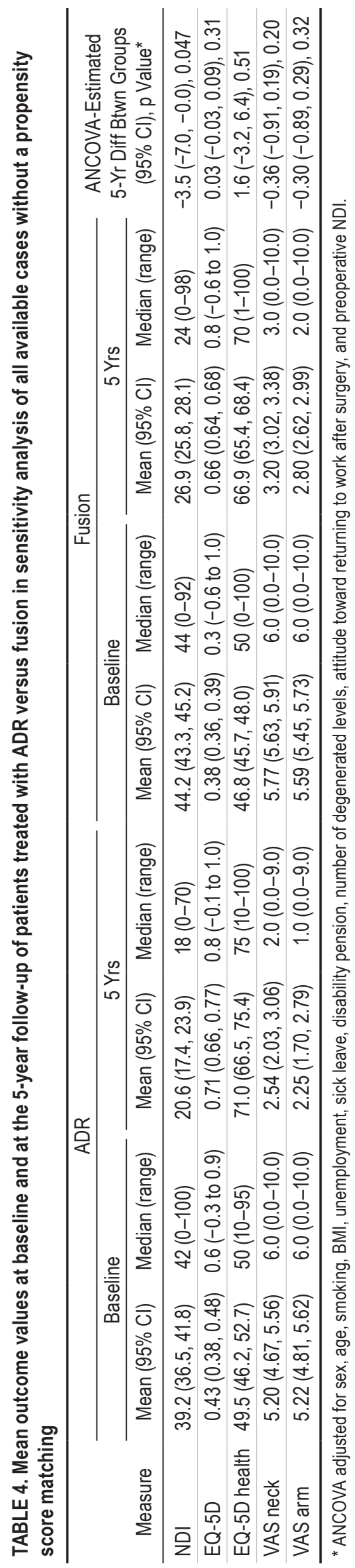

groups: the patients receiving arthroplasty were younger, had less impairment of fine motor skills, had lower NDIs at baseline, and were more positive toward returning to work than the patients receiving fusion surgery. After matching, there were no statistical differences, and none of the adjustments of our estimates precluded clinically important differences between the ADR group and the fusion surgery group at any point, despite the fact that both groups halved their NDI scores. Our finding is consistent with our RCT ${ }^{11}$ and the previous IDE studies. . $^{2,5,8,15,16,22,24}$ In fact, the outcome 5 years after surgical treatment for cervical radiculopathy has recently been discovered to be more dependent on preoperative mental distress, such as anxiety and depression, than the chosen surgical method, whether ADR or fusion. ${ }^{12}$

The ADR group, however, had more perioperative complications, more secondary surgeries on the index level, and the same incidence of secondary surgery on adjacent levels compared with the fusion group. Hence, ADR surgery required more revisions and did not prevent progression of clinical ASP, one of the main arguments for the use of this device. Our results regarding secondary surgery from this observational study support our findings from the RCT, which we have reported separately. ${ }^{11}$ It has been suggested that the high incidence of loosening and subsidence could be related to the type of implant used, which was an unconstrained device in the RCT. ${ }^{14}$

Our present study using the Swespine register, however, includes several types of ADR devices, both semiconstrained and unconstrained, and still shows more indexrelated secondary surgeries in the arthroplasty group. ${ }^{17,25}$ The clear disparity in prevalence of procedures may reflect the overall experience and facility with ACDF as opposed to ADR, and surgeons who are early in the learning curve with ADR may be more likely to revise implants if the outcome is not as expected. Patients' expectations for ADR may be different than those for ACDF, and therefore may have a lower threshold for reoperation at the index level if those expectations are not met. Our results contradict those of other large RCTs with a 5-year follow-up; 2,5 i.e., they report a higher frequency of secondary surgery in the control group compared with the ADR group, mostly because of nonunion. Such a discrepancy might be a result of whether pseudarthrosis is decided on the basis of radiographs alone or if the diagnosis is made only if the patient has severe symptoms together with signs of nonunion on radiographs. Variation in indications for when to use the nonunion diagnosis could also explain the differences in results between the studies.

Our study has several strengths. First, Swespine is a nationwide register in which validated instruments are used with prospective collected data. Second, in 2016, $90 \%$ of the spine clinics in Sweden were affiliated and the register completeness was $75 \%$ (www.swespine.se). ${ }^{7,26,27}$ Therefore, these results reflect a national setting and not just a few clinics or surgeons. Compared with earlier publications, our study differed because there were no sponsors from arthroplasty manufacturers, which might explain the results regarding higher complication rates and secondary surgery in the arthroplasty group compared with those that have been reported from IDE studies. ${ }^{1,2,5,8,15,16,22,24}$ 
Our study has some limitations that merit discussion. First, the major limitation of our study is the observational design, although pseudo-randomization creating comparable groups with propensity score matching was used. We cannot rule out residual confounding and differential selection of patients to each group. Second, there were many patients lost to follow-up: $32 \%$ in year 2 and 34\% in year 5 . However, all patients in the primary propensity scorematched analysis had 5-year follow-up data. Third, not all complications and reoperations are reported in Swespine. ${ }^{20}$ However, we find it unlikely that this is device related, and it should therefore affect both treatment groups equally. A last limitation is that there were a variety of artificial discs used, including at least one that is no longer available and others that were unknown because some surgeons fail to report which specific implant has been used. Then, as now, information is sparse regarding whether certain discs are better than others, which might have negatively impacted the arthroplasty group. However, this is not an RCT; instead, this observational study shows how different surgeons and implants will in fact vary widely in a national setting.

\section{Conclusions}

We found no clinically significant differences in primary or secondary outcomes between the ADR and fusion groups after anterior decompression of cervical radiculopathy, in the short term or during long-term follow-up.

\section{Acknowledgments}

We thank Carina Blom at the Swedish Society of Spinal Surgeons and the Swedish Spine Study Group for handling the Swedish Spine Registry.

\section{References}

1. Alvin MD, Abbott EE, Lubelski D, Kuhns B, Nowacki AS, Steinmetz MP, et al: Cervical arthroplasty: a critical review of the literature. Spine J 14:2231-2245, 2014

2. Burkus JK, Haid RW Jr, Traynelis VC, Mummaneni PV: Long-term clinical and radiographic outcomes of cervical disc replacement with the Prestige disc: results from a prospective randomized controlled clinical trial. J Neurosurg Spine 13:308-318, 2010

3. Carreon LY, Glassman SD, Campbell MJ, Anderson PA: Neck Disability Index, short form-36 physical component summary, and pain scales for neck and arm pain: the minimum clinically important difference and substantial clinical benefit after cervical spine fusion. Spine J 10:469474, 2010

4. Chin-See-Chong TC, Gadjradj PS, Boelen RJ, Harhangi BS: Current practice of cervical disc arthroplasty: a survey among 383 AOSpine International members. Neurosurg Focus 42(2): $\mathrm{E} 8,2017$

5. Delamarter RB, Zigler J: Five-year reoperation rates, cervical total disc replacement versus fusion, results of a prospective randomized clinical trial. Spine (Phila Pa 1976) 38:711-717, 2013

6. Frankel HL, Hancock DO, Hyslop G, Melzak J, Michaelis LS, Ungar GH, et al: The value of postural reduction in the initial management of closed injuries of the spine with paraplegia and tetraplegia. I. Paraplegia 7:179-192, 1969

7. Fritzell P, Hägg O, Gerdhem P, Abbott A, Songsong A, Parai C, et al: Swespine Annual Report 2017. Swedish Society of
Spinal Surgeons (4s.nu/pdf/170925_Svenska_ryggregistret_ arsrapport\%202017_SENT.pdf) [Accessed August 16, 2018]

8. Hacker FM, Babcock RM, Hacker RJ: Very late complications of cervical arthroplasty: results of 2 controlled randomized prospective studies from a single investigator site. Spine (Phila Pa 1976) 38:2223-2226, 2013

9. Hernán MA, Hernández-Díaz S, Werler MM, Mitchell AA: Causal knowledge as a prerequisite for confounding evaluation: an application to birth defects epidemiology. Am J Epidemiol 155:176-184, 2002

10. Hilibrand AS, Carlson GD, Palumbo MA, Jones PK, Bohlman HH: Radiculopathy and myelopathy at segments adjacent to the site of a previous anterior cervical arthrodesis. J Bone Joint Surg Am 81:519-528, 1999

11. MacDowall A, Canto Moreira N, Marques C, Skeppholm M, Lindhagen L, Robinson Y, et al: Artificial disc replacement versus fusion in patients with cervical degenerative disc disease with radiculopathy: 5-year outcomes. J Neurosurg Spine [in press], 2018

12. MacDowall A, Skeppholm M, Lindhagen L, Robinson Y, Olerud C: Effects of preoperative mental distress versus surgical modality, arthroplasty, or fusion on long-term outcome in patients with cervical radiculopathy. J Neurosurg Spine 29:371-379, 2018

13. MacDowall A, Skeppholm M, Robinson Y, Olerud C: Validation of the visual analog scale in the cervical spine. J Neurosurg Spine 28:227-235, 2018

14. Mo Z, Zhao Y, Du C, Sun Y, Zhang M, Fan Y: Does location of rotation center in artificial disc affect cervical biomechanics? Spine (Phila Pa 1976) 40:E469-E475, 2015

15. Mummaneni PV, Burkus JK, Haid RW, Traynelis VC, Zdeblick TA: Clinical and radiographic analysis of cervical disc arthroplasty compared with allograft fusion: a randomized controlled clinical trial. J Neurosurg Spine 6:198-209, 2007

16. Murrey D, Janssen M, Delamarter R, Goldstein J, Zigler J, Tay B, et al: Results of the prospective, randomized, controlled multicenter Food and Drug Administration investigational device exemption study of the ProDisc-C total disc replacement versus anterior discectomy and fusion for the treatment of 1-level symptomatic cervical disc disease. Spine J 9:275-286, 2009

17. Nandyala SV, Marquez-Lara A, Fineberg SJ, Singh K: Comparison of revision surgeries for one- to two-level cervical TDR and ACDF from 2002 to 2011. Spine J 14:2841-2846, 2014

18. Nesterenko SO, Riley LH III, Skolasky RL: Anterior cervical discectomy and fusion versus cervical disc arthroplasty: current state and trends in treatment for cervical disc pathology. Spine (Phila Pa 1976) 37:1470-1474, 2012

19. Nunley PD, Jawahar A, Cavanaugh DA, Gordon CR, Kerr EJ III, Utter PA: Symptomatic adjacent segment disease after cervical total disc replacement: re-examining the clinical and radiological evidence with established criteria. Spine J 13:5-12, 2013

20. Öhrn A, Olai A, Rutberg H, Nilsen P, Tropp H: Adverse events in spine surgery in Sweden: a comparison of patient claims data and national quality register (Swespine) data. Acta Orthop 82:727-731, 2011

21. Parker SL, Godil SS, Shau DN, Mendenhall SK, McGirt MJ: Assessment of the minimum clinically important difference in pain, disability, and quality of life after anterior cervical discectomy and fusion: clinical article. J Neurosurg Spine 18:154-160, 2013

22. Phillips FM, Geisler FH, Gilder KM, Reah C, Howell KM, McAfee PC: Long-term outcomes of the US FDA IDE prospective, randomized controlled clinical trial comparing PCM cervical disc arthroplasty with anterior cervical discectomy and fusion. Spine (Phila Pa 1976)40:674-683, 2015

23. Ranawat CS, O’Leary P, Pellicci P, Tsairis P, Marchisello P, 
Dorr L: Cervical spine fusion in rheumatoid arthritis. J Bone Joint Surg Am 61:1003-1010, 1979

24. Sasso RC, Anderson PA, Riew KD, Heller JG: Results of cervical arthroplasty compared with anterior discectomy and fusion: four-year clinical outcomes in a prospective, randomized controlled trial. J Bone Joint Surg Am 93:1684-1692, 2011

25. Skeppholm M, Henriques T, Tullberg T: Higher reoperation rate following cervical disc replacement in a retrospective, long-term comparative study of 715 patients. Eur Spine J 26:2434-2440, 2017

26. Strömqvist B, Fritzell P, Hägg O, Jönsson B: The Swedish Spine Register: development, design and utility. Eur Spine J 18 (Suppl 3):294-304, 2009

27. Strömqvist B, Jönsson B, Fritzell P, Hägg O, Larsson BE, Lind B: The Swedish national register for lumbar spine surgery: Swedish society for spinal surgery. Acta Orthop Scand 72:99-106, 2001

28. White IR, Royston P, Wood AM: Multiple imputation using chained equations: issues and guidance for practice. Stat Med 30:377-399, 2011

29. Young IA, Cleland JA, Michener LA, Brown C: Reliability, construct validity, and responsiveness of the Neck Disability Index, Patient-Specific Functional Scale, and Numeric Pain Rating Scale in patients with cervical radiculopathy. Am J Phys Med Rehabil 89:831-839, 2010

\section{Disclosures}

Dr. MacDowall serves on the board of the Swedish Society of Spinal Surgeons. Dr. Skeppholm is a member of the speaker's bureau for DePuy Synthes Spine. Dr. Robinson is a member of the speaker's bureau and/or gives paid presentations for AOSpine, DePuy Synthes Spine, and Medtronic. He is also on the boards of the Cervical Spine Research Society (European Section) and AOSpine. Dr. Olerud is a member of the speaker's bureau for Anatomica, AOSpine, DePuy Synthes, and Medtronic, and he also serves on the board of Cervical Spine Research Society (European Section).

\section{Author Contributions}

Conception and design: MacDowall, Olerud. Acquisition of data: MacDowall, Löfgren. Analysis and interpretation of data: MacDowall. Drafting the article: MacDowall. Critically revising the article: Michaëlsson, Olerud. Reviewed submitted version of manuscript: Skeppholm, Robinson, Michaëlsson, Olerud. Approved the final version of the manuscript on behalf of all authors: MacDowall. Statistical analysis: Lindhagen. Administrative/technical/ material support: Löfgren. Study supervision: Skeppholm, Robinson, Olerud.

\section{Supplemental Information \\ Previous Presentations}

Portions of this work were presented in abstract form at the Cervical Spine Research Society's 34th Annual Meeting, held in Lisbon, Portugal, on May 9-11, 2018.

\section{Correspondence}

Anna MacDowall: Uppsala University, Uppsala, Sweden. anna. macdowall@surgsci.uu.se. 